
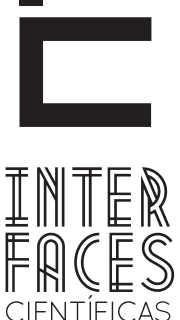

HUMANASE SOCIAIS

\title{
CONSTRUINDO UMA ESTRATÉGIA: O BALANCED SCORECARD (BSC) COMO FERRAMENTA ESTRATÉEICA EM UM CURSO DE IDIOMAS DA CIDADE DE FEIRA DE SANTANA-BA
}

Jocely Santos Caldas Almeida ${ }^{2}$
Marta G. Moraes de Figueiredo ${ }^{2}$

\section{RESUMO}

0 presente artigo tem como principal propósito conhecer e interpretar a realidade do processo de formulação de uma estratégia com a utilização do Balanced Scorecard - BSC, em uma escola de idiomas na cidade de Feira de Santana-Ba. Como procedimento metodológico, realizou-se uma pesquisa bibliográfica e após embasamento teórico desenvolveu-se estudo de caso com pesquisa in loco na escola, objeto deste estudo. Como resultado, verificou-se que a utilização do BSC permitiu a articulação da estratégia e auxiliou no alinhamento das diligências grupais, das específicas por cargo e das iniciativas organizacionais, desde quando o mapa e os quadros geraram uma visualização mental essencial para o desenvolvimento da respectiva trajetória estratégica. Concluiu-se, portanto, que o BSC pode ser aplicado em organizações pequenas baseado em termos similares aos utilizado sem grandes organizações apoiando e viabilizando a formulação da estratégia.

\section{PALAVRAS-CHAVE}

Balanced Scorecard. Estratégia. Planejamento. Escola de Idioma 


\section{ABSTRACT}

The main purpose of this paper is to understand and analyze the reality of the process of formulating a strategy using the Balanced Scorecard-BSC in a Language Course from Feira de Santana (BA). Bibliographic research, theoretical basement and a local survey where used as methodological procedure. As a result, the use of BSC strategy allowed the articulation and it was found that the BSC also assisted in aligning the steps group, the specific charge and the organizational initiatives, since when the map and the frames generated mental visualization which was essential for the development of their strategic trajectory. The conclusion was that the BSC can be applied in small organizations based on similar terms to those used without major organizations supporting and enabling the formulation of strategy.

\section{KEYWORDS}

Balanced Scorecard. Strategy. Planning. Language Course.

\section{INTRODUÇ̄̃O}

As organizações, de um modo geral, estão vivenciando um período de grande dinâmica ambiental. 0 ambiente está envolto em um cenário de constantes incertezas, complexidade e mudanças, o que exige flexibilidade por parte das mesmas a fim de se tornar/manter competitiva no mercado. Neste contexto, os gestores precisam ter entendimento desta dinâmica a fim de conseguirem se posicionar e tomar decisões de forma rápida e embasada.

As organizações que não percebem esta variação ambiental correm o risco real de verem seus empreendi-

\section{RESUMEN}

Este artículo tiene como objetivo principal conocer e interpretar la realidad del proceso de formulación de una estrategia de uso del Balanced Scorecard - BSC en una escuela de idiomas en la ciudad de Feira de Santana-BA. Como procedimiento metodológico se llevó a cabo una búsqueda en la literatura y después de las bases teóricas, se ha desarrollado La investigación teórica in situ en la escuela, objeto de estudio de este trabajo. Como resultado, ha sido verificado que el uso de la estrategia de BSC permite la articulación estratégica y asiste en la organización de diligencias de grupo, de funciones específicas y de las iniciativas de la organización, desde cuando el mapa y los cuadros generaron una visualización mental y esencial al desarrollo sus trayectorias estratégicas. Se concluye, por lo tanto, que el BSC se puede aplicar en pequeñas organizaciones basadas en términos similares a los utilizados en las grandes organizaciones, de manera a asistir y permitir la formulación de la estrategia.

\section{PALABRAS CLAVE}

Balanced Scorecard. Estrategia. Planificación. Escuela de Idiomas

mentos não alcançarem os objetivos traçados ou de não conseguirem manter e melhorar os resultados obtidos. Desta forma, é mister que os principais tomadores de decisão nos ambientes organizacionais, em qualquer nível, estejam subsidiados por informações reais que possibilitem a relação entre os processos operacionais e gerenciais com a visão e missão da empresa.

Segundo Kaplan e Norton (2000), o Balanced Scorecard - BSC traduz a missão e a estratégia de uma organização, em uma série de medidas de desempe- 
nho, que servem para a empresa medir a situação em que se encontra em relação aos resultados almejados.

Neste contexto, o presente artigo tem como principal propósito conhecer e interpretar a realidade do processo de formulação de uma estratégia. Como objeto de estudo utilizou-se uma escola de idiomas na cidade de Feira de Santana - a Escola OPERA Idiomas - por esta estar passando por um processo de redese- nho do seu planejamento estratégico, buscando utilizar o BSC como instrumento de intervenção em seu processo de definição de estratégia.

Destarte, buscou-se utilizar como metodologia uma pesquisa bibliográfica e, após embasamento teórico, desenvolveu-se estudo de caso com pesquisa in loco na escola, objeto deste estudo.

\section{ESTRATÉGIA EMPRESARIAL}

O termo estratégia apresenta diferentes definições, o que demonstra um processo evolutivo de adaptação das organizações ao ambiente interno e externo o qual vivenciam. No contexto histórico, a origem do conceito de estratégia encontra-se no campo militar. A palavra tem origem no grego strategos, arte de um general do exército. No campo da administração, está associada às decisões tomadas a nível organizacional, para estabelecerem as condições presentes e futuras da empresa em relação ao ambiente.

As corporações estão vivendo cada vez mais em ambientes de constantes mudanças. A globalização vem exigindo um desempenho diferenciado por parte das empresas que buscam atuar com maior capacidade de reação; além de lançar novos bens e serviços mais rapidamente, atender a demanda com tempos de espera menores e conquistar maior confiabilidade por parte dos clientes. A crescente competição vem forçando as organizações a desenvolverem instrumentos que garantem sua vantagem competitiva a partir da elaboração de estratégias bem definidas, o que visa manter um alinhamento entre os objetivos, a missão e visão da organização.

Para Porter (2004) a busca da Vantagem Competitiva está na essência da formulação estratégica, que é lidar com a competição. Em momento de "luta” por participação no mercado, a competição não ocorre apenas em relação aos concorrentes, mas em toda a cadeia de relações da empresa. A estratégia empresarial surge desta forma, como uma ferramenta importante para nortear a organização na busca por participação no mercado ou na busca por recolocação no mercado.

Estratégia Empresarial é defendida pelos gestores e executivos organizacionais como uma arma para o alcance de objetivos e o domínio da competitividade. Para Slack (1997, p. 58),

Estratégia é o padrão geral de decisões e ações que posicionam a organização em seu ambiente e que pretendem alcançar suas metas de longo prazo. Uma estratégia possui conteúdo e processo. 0 conteúdo de uma estratégia diz respeito às decisões específicas que são tomadas para alcançar objetivos específicos.

Esta ideia, definida por Slack, é corroborada pelo pensamento de Ansoff (1977) o qual afirma que a estratégia enfatiza a análise racional em termos de alta cúpula da empresa, em que os objetivos são essenciais na orientação, avaliação de desempenho e na consecução dos propósitos organizacionais, os quais devem ser coerentes com seu "perfil de potencialidades". 
Segundo ANDREWS, (1971, p. 28),

A estratégia corporativa é o padrão dos maiores objetivos, propósitos ou metas e políticas essenciais e planos para alcançar aquelas metas, declarados de uma forma que defina em que negócio a companhia está ou deveria estar e o tipo de companhia que é ou deveria ser.

Para Mintzberg (1992) a palavra estratégia é utilizada de diferentes formas por gestores e autores da área, em vista disso ele apresenta cinco definições que podem ser aplicadas a estratégia: estratégia como plano, como manobra (ploy), como padrão, como posição e como perspectiva. Como plano, estabelece conscientemente, diretrizes para um curso de ação, sendo elaborada antes das ações para as quais elas se aplicam. Como manobra (ploy) é vista como uma forma de ganhar vantagem sobre um adversário ou competidor. Como padrão consiste no comportamento resultante de um fluxo de ações. A estratégia como padrão é consistente no comportamento quer seja ou não intencional.

0 que se abstrai nestas definições é que as organizações precisam ter claramente definidas quais são os principais objetivos para que os gestores consigam promover o alinhamento dos mesmos com a capacidade de desenvolvimento da organização. Observa-se que, neste contexto, é necessário o conhecimento da organização como um todo, desenvolvendo uma visão sistêmica no intuito de conseguir oferecer bens e serviços que atendam as necessidades dos clientes e as expectativas dos stakeholders, os principais interessados na organização.

Dessa forma, entende-se que há grande complexidade na definição de objetivos organizacionais que norteiam a formulação de estratégias que atendam as citadas expectativas; o que demonstra a importância da utilização de metodologia auxiliadora do desenvolvimento de um modelo estratégico que traga vantagem competitiva a organização. Surge, neste contexto, o BSC como uma ferramenta gerencial alternativa, que vai auxiliar na implementação das estratégias empresariais embasadas no levantamento e associação dos fatores de desempenho com os indicadores de resultado na perspectiva financeira.

visão rápida, embora abrangente, de toda a empresa" (KAPLAN; NORTON 2004, p. 8).

O BSC surge no momento em que os métodos tradicionais de avaliação de desempenho já não traduzem os resultados de maneira adequada à tomada de decisão por parte dos gestores. A dinâmica ambiental exige das organizações uma maneira mais rápida de avaliar a organização de uma maneira mais ampla, conduzindo os gestores a tomarem decisões baseados em um referencial mais abrangente a respeito dos seus problemas. Nota-se que, desde sua criação, 
vários relatos de sua implantação, com sucesso em grandes empresas a nível mundial, vem sendo descrita nos diversos meios bibliográficos.

Nesta visão, MacDonald (2003, p. 34) determina que,

\begin{abstract}
O BSC desempenha sua principal função, quando utiliza indicadores que precisam fazer parte de um sistema de comunicação, informação e aprendizado dos colaboradores em todos os níveis hierárquicos da organização, realizando a conexão entre a formulação e a implementação das estratégias já existentes na organização, permitindo assim o equilíbrio, estabelecimento e divulgação de seus objetivos estratégicos no planejamento e controle empresarial.
\end{abstract}

Autores determinam que a principal função do BSC é traduzir a estratégia, a missão e visão da empresa em aspectos/objetivos tangíveis a fim de que se consiga ter um maior controle e avaliação do desempenho (BIMBATI; TOLEDO, 2000). Observa-se que para alcançar este objetivo, o BSC indica que é necessário comunicar e associar objetivos e medidas estratégicas, planejar, estabelecer metas e alinhar iniciativas estratégicas, melhorar o feedback e o aprendizado estratégico.

Infere-se, então, que o BSC cria uma estrutura, uma linguagem para comunicar a missão e estratégia, e utiliza indicadores para informar os funcionários sobre os caminhos que conduzem ao sucesso no presente e no futuro. Ao articularem os resultados desejados pela empresa com os vetores desse resultado, os executivos esperam canalizar as energias, as habilidades e os conhecimentos específicos das pessoas na empresa inteira, para alcançar as metas de longo prazo. (KAPLAN; NORTON, 2004)

Segundo Rocha e Oliveira (2006), o BSC transforma a missão e estratégia em objetivos e medidas, organizados de acordo com quatro perspectivas diferentes: financeira, do cliente, dos processos internos e do aprendizado e crescimento, traduzindo as medidas estratégicas de alto nível (subjetivas) em medidas específicas de nível operacional (objetivas). A Figura 1 demonstra estas quatro perspectivas:

FIGURA 1 - TRADUÇÃO DA VISÃO E ESTRATÉGIA: QUATRO PERSPECTIVAS

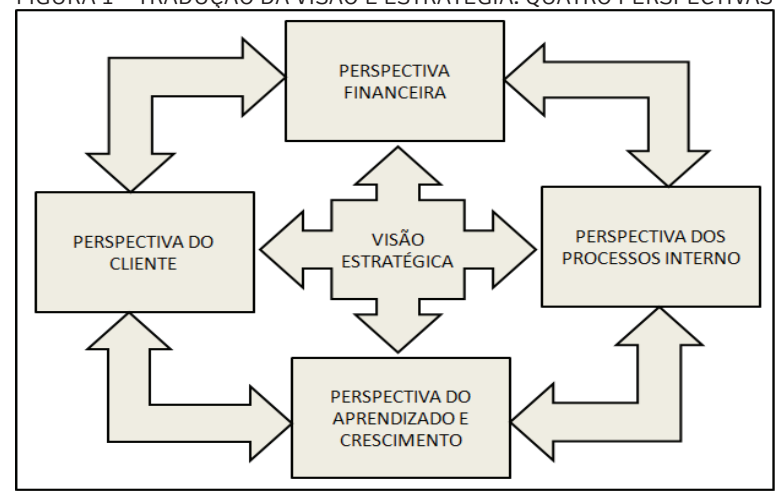

Fonte: Adaptado de Kaplan e Norton (2004)

Rocha e Lavardi (2008) baseados nos estudos de Bimbatti e Toledo (2002) e Rezende (2003), demonstram as quatro perspectivas apresentadas pela metodologia do BSC, e as características pertinentes a cada uma delas, a saber:

a) Perspectiva Financeira: abrange o crescimento e o perfil da receita, a melhoria da produtividade e a redução de custos, além da utilização de ativos em relação à estratégia de investimento. b) Perspectiva do Cliente: as empresas identificam os segmentos de clientes e mercado nos quais desejam competir, dessa forma, as empresas alinham suas medidas básicas de resultados relacionados aos clientes, como: satisfação, fidelidade, retenção, captação e lucratividade, com segmentos específicos de clientes e mercado. c) Perspectiva Processos internos: os executivos procuram conhecer os processos críticos que devem ser melhorados na empresa assim, buscando a excelência, a fim de atender aos objetivos dos acionistas e dos clientes. d) Perspectiva Aprendizagem e Crescimento: pilares da estratégia organizacional contextualizada à sociedade do conhecimento, competências essenciais, capacidades e comportamento organizacional. As habilidades e conhecimentos organizacionais são indispensáveis para se manter competitivo. 
Observa-se que dentro destas perspectivas, o BSC permite à empresa o acompanhamento de sua trajetória através dos controles financeiros, sem dispensar a construção de capacidades e aquisição de ativos intangíveis para um crescimento futuro. Isso implica que o BSC deve ser desenvolvido em um ambiente onde as pessoas estejam envolvidas e motivadas no processo, pois a sua aplicação está relacionada à mudança da cultura organizacional e esta só acontece se houver o envolvimento das pessoas.

\section{PROCEDIMENTOS METODOLÓGICOS}

O propósito desta pesquisa é buscar conhecer e interpretar a realidade do processo de formulação de uma estratégia, sem nela interferir para modificá-la. Portanto, conforme Vergara (1997) trata-se de um estudo com caráter descritivo e transversal, no qual há coleta de informações somente uma vez no tempo.

No que diz respeito às técnicas de pesquisa, estas se dividem em duas fases: inicialmente, foi utilizada a pesquisa bibliográfica, através de livros e artigos coma função de elucidar o conteúdo concernente ao tema escolhido. A partir da pesquisa teórica acerca do processo de formulação de estratégias, identificou-se, na revisão de literatura, a importância de "Indicadores Balanceados de Desempenho" no sentido de obter a relação causa-efeito e perceber o papel dos mapas estratégicos como ferramentas de apoio aos gestores na execução, implementação e controle da estratégia.

Efetuada a revisão teórica, passou-se à operacionalização da ferramenta. Neste momento, foi selecionada na cidade de Feira de Santana, interior da Bahia uma empresa que atua no setor educacional livre, mais especificamente, ensino de idiomas que vem passando por um processo de redesenho do planejamento estratégico. 0 estudo, na empresa citada, foi realizado durante o mês de setembro de 2012 e fez uso de informações oriundas do planejamento estratégico da organização, assim como da técnica de uso dos mapas estratégicos que "mostram a causa e efeito das ligações pelo qual melhoramentos específicos criam resultados desejados" (COSTA, 2006).
Nesta etapa também foram adotados métodos de levantamento de dados primários, os quais possibilitaram o registro sobre a construção do BSC (Balanced Scorecard) em anos passados como importante ferramenta para medir o desempenho da empresa, a partir das quatro grandes perspectivas adotadas por este.

Referente à análise dos dados, o estudo adota a abordagem qualitativa, a qual, segundo Malhotra (2001), pode ser definida como uma metodologia que produz dados a partir de observações, baseada em pequenas amostras, que auxilia na compreensão do contexto do problema. Nesta fase, faz-se a ressalva que o estudo realizado junto à empresa aborda o BSC, restringindo-se apenas ao mapa e ao painel de desempenho, portanto, os resultados obtidos no processo de elaboração do mapa estão limitados à organização pesquisada, não podendo estas conclusões serem aplicadas em outras empresas ainda que do mesmo setor. 


\section{ANÁLISE DOS RESULTADOS}

No contexto da organização, objeto deste estudo,que atua no setor educacional da cidade de Feira de Santana, interior da Bahia, existe um processo de elaboração da estratégia próximo aos conceitos abordados por Henry Mintzberg, a partir do momento em que a empresa acredita que tanto análise como intuição são ferramentas importantes na confecção das estratégias. Somado a esta concepção, observa-se que a empresa também, primordialmente, elabora seu planejamento estratégico embasado no BSC (BALANCED SCORECARD), de modo a "atuar ao mesmo tempo como um modelo de avaliação e uma filosofia de gestão."(REZENDE, 2003)

O curso OPERA IDIOMAS LTDA é uma empresa brasileira, fundada em 1999 na cidade de Feira de Santana e sua escolha aconteceu por conta do seu crescimento significativo em um setor onde imperam franquias nacionais, adicionado ao fato de utilizar um planejamento embasado no BSC e através desta ferramenta, tem conquistado desempenho expressivo neste setor. A empresa iniciou suas atividades com 30 alunos e terminou o primeiro semestre de $2012 \mathrm{com}$ 543 alunos. Esta oferece como produto, cursos de inglês, francês e espanhol para um público alvo formado por crianças a partir dos três anos, adolescentes e adultos, com qualidade elevada e preço acessível. Para chegar a estes números, a direção informou que em 2009 foi elaborado um planejamento estratégico contemplando os quatro anos seguintes (2010 a 2013) e concordou em demonstrar como aconteceu o processo de construção do BSC.

Foi verificado junto à direção da empresa que a necessidade de planejar estrategicamente é resultado de dois conjuntos de forças: o primeiro conjunto compreende as oportunidades e os desafios criados pelos segmentos do ambiente, como concorrência - composta em grande número por modelos de franquias, consumidores e mão de obra especializada. 0 segun- do conjunto é composto por problemas e as oportunidades que surgem dentro da empresa, como as competências de seus funcionários, processos internos, disponibilidades de capital e outros elementos.

Neste processo, foram revistos elementos relativos aos seguintes aspectos: missão, visão, valores e princípios organizacionais, bem como em relação ao ambiente (pontos fracos, fortes, ameaças e oportunidades). Dentre eles, destaca-se a missão da organização, descrita pelo curso como: "Promover o ensino de idiomas com total qualidade e comprometimento, possibilitando o conhecimento de diversas culturas estrangeiras e contribuindo para o crescimento profissional e intelectual de todos que estudam e trabaIham na instituição".

Este elemento estabelece o propósito ou as razões da existência da empresa, do ponto de vista de sua utilidade para os clientes. Por isso, ao identificar a missão, passa-se a melhor entender qual a necessidade do mercado a qual a empresa atende. Outro ponto importante se refere à visão, que afeta a escolha da estratégia, pois a mesma determina os objetivos e as metas atingíveis, bem como a suas limitações de recursos. A empresa defende sua visão como: "Atuar no mercado visando excelência do desenvolvimento pessoal e profissional, servindo de referência em escola de idiomas na Bahia e no Brasil."

Outra importante etapa do planejamento estratégico é a análise do ambiente, no qual são estabelecidos os contextos em que a organização atua. Destaca-se que é a partir deste ponto que se introduz a apresentação do processo de operacionalização e apresentação do BSC. Para tanto, buscou-se correlacionar os pontos fracos e as ameaças com os objetos emergentes, os quais compõem o mapa, representados na figura 1. Tais informações, advindas da análise do ambiente, viabilizam a identificação dos objetivos 
emergentes e a perspectiva com a qual os mesmos es tão relacionados. Deste modo, foi possível obter um primeiro esboço do quadro abaixo, importante para alimentar e construir o mapa estratégico.

FIGURA 2- QUADRO PARA CONSTRUÇÃO DO MAPA ESTRATÉGICO

\begin{tabular}{|c|c|c|}
\hline PONTOS FRACOS & OBJETIVOS EMERGENTES & PERSPECTIVA \\
\hline Estrutura física & Qualidade da estrutura & Cliente \\
\hline Forma limitada de pagamento & Satisfação & Cliente/ Financeiro \\
\hline Dificuldade em captar mais serviços & Fidelização & Processos internos \\
\hline Rigor na avaliação de estudantes adultos & Retenção & Cliente \\
\hline Vícios no trabalho & Retrabalho & Processos internos \\
\hline $\begin{array}{l}\text { Dificuldade em captar professores capacitados } \\
\text { em curto prazo }\end{array}$ & Seleção externa & Processos internos \\
\hline AMEAÇAS & OBJETIVOS EMERGENTES & PERSPECTIVA \\
\hline Cursos online, ead & Crescimento & Cliente \\
\hline $\begin{array}{l}\text { Cursos de outro segmento atuando em } \\
\text { treinamento empresarial } \\
\text { com preços mais baixos }\end{array}$ & Ampliação & Cliente \\
\hline Mão de obra escassa & Fidelização do quadro interno & Processos internos \\
\hline OPORTUNIDADES & OBJETIVOS EMERGENTES & PERSPECTIVA \\
\hline $\begin{array}{l}\text { Cursos online, ead } \\
\text { Novos cursos profissionalizantes }\end{array}$ & $\begin{array}{l}\text { Ampliação } \\
\text { Crescimento }\end{array}$ & $\begin{array}{l}\text { Cliente } \\
\text { Cliente }\end{array}$ \\
\hline PONTOS FORTES & OBJETIVOS EMERGENTES & PERSPECTIVA \\
\hline Professores capacitados & Treinamento constante & Processos internos \\
\hline Preço & Satisfação & Cliente \\
\hline Metodologia diferenciada & Fidelização & Cliente \\
\hline
\end{tabular}

FONTE: Primária

Feito este quadro, a elaboração do BSC seguiu as seguintes atividades:

Foram definidos, por meio de debate envolvendo a direção, coordenação e supervisão do curso os temas estratégicos da organização nas quatro perspectivas: financeira, clientes, processos internos e aprendizado e crescimento. Em seguida, foram traçados os objeti- vos estratégicos em cada uma das quatro perspectivas. 0 processo iniciou-se da perspectiva financeira, apoiando-se no planejamento estratégico, bem como do seu respectivo tema estratégico. 0 processo foi repetido, na seqüência, para as perspectivas de clientes, dos processos internos e de aprendizado e crescimento como pode ser analisado no quadro abaixo: 
FIGURA 3- PERSPECTIVAS, METAS E AÇÕES

\begin{tabular}{|c|c|c|c|c|}
\hline PERSPECTIVAS & MAPA & OBJETIVOS & METAS & AÇÕES \\
\hline FINANCEIRA & Lucro & Crescimento & Aumento em $10 \%$ & Crescimento anual de $10 \%$ \\
\hline CLIENTES & $\begin{array}{l}\text { Qualidade no aten- } \\
\text { dimento } \\
\text { Serviços adicio- } \\
\text { nais }\end{array}$ & $\begin{array}{l}\text { Fidelização dos alu- } \\
\text { nos } \\
\text { Satisfação dos alu- } \\
\text { nos e indicação de } \\
\text { novos pelos antigos }\end{array}$ & $\begin{array}{l}\text { Aumento de matri- } \\
\text { culas em } 20 \% \\
\text { e retenção de } 75 \%\end{array}$ & $\begin{array}{l}\text { Oferecer cursos voltados aos jo- } \\
\text { gos olímpicos e atividades adicio- } \\
\text { nais ao ensino de idiomas volta- } \\
\text { das para crianças e adolescentes. }\end{array}$ \\
\hline $\begin{array}{l}\text { PROCESSOS INTER- } \\
\text { NOS }\end{array}$ & $\begin{array}{l}\text { Padronização de } \\
\text { processos de con- } \\
\text { versa entre pais e } \\
\text { professores e lan- } \\
\text { çamento de notas. } \\
\text { Padronização de } \\
\text { pesquisas internas } \\
\text { e externas. } \\
\text { Participação nos } \\
\text { eventos }\end{array}$ & $\begin{array}{l}\text { Qualidade de co- } \\
\text { municação com os } \\
\text { responsáveis e en- } \\
\text { vio de notas. } \\
\text { Eficiência } \\
\text { Incentivo aos alu- } \\
\text { nos }\end{array}$ & $\begin{array}{l}100 \% \\
\\
\text { Aumento } \\
50 \% \\
100 \%\end{array}$ & $\begin{array}{l}\text { Modificar o sistema de infor- } \\
\text { mações. } \\
\text { Aumentar a comunicação } \\
\text { com os estudantes e pais atra- } \\
\text { vés de portal da internet. } \\
\text { Otimizar pesquisas de satisfação } \\
\text { através de mail-marketing. } \\
\text { Solucionar pendências no prazo } \\
\text { Maximo de 48h. } \\
\text { Criar o manual da recepção. }\end{array}$ \\
\hline $\begin{array}{l}\text { APRENDIZADO E } \\
\text { CRESCIMENTO }\end{array}$ & Motivação & $\begin{array}{l}\text { Qualidade de vida } \\
\text { no trabalho }\end{array}$ & Aumentar em $20 \%$ & $\begin{array}{l}\text { Reuniões mensais com professo- } \\
\text { res. } \\
\text { Oferecer treinamento de profes- } \\
\text { sores a cada } 3 \text { meses ou } 4 \text { vezes } \\
\text { ao ano. } \\
\text { Oferecer treinamento de recep- } \\
\text { cionistas duas vezes ao ano. }\end{array}$ \\
\hline
\end{tabular}

FONTE: Primária, baseado no planejamento estratégico da empresa

Traçados os objetivos estratégicos, a etapa seguinte aconteceu através de uma reunião com a direção, professores e recepcionistas da empresa a fim de desenhar o mapa estratégico. Iniciou-se, então a definição das relações de causa e efeito dentro das próprias perspectivas. Como pode ser visto na figura abaixo:
Reuniões com a presença da direção, professores e recepcionistas foram realizadas com a finalidade de se elencar os possíveis indicadores de desempenho para cada objetivo estratégico identificado. 0 processo iniciou-se, novamente, na perspectiva financeira, objetivo por objetivo. A discussão sobre os indicado- 
res progrediu para as outras perspectivas, na mesma

ordem que as demais argumentações.

\section{FIGURA 4 - MAPA ESTRATÉGICO}

\section{BALANCED SCORECARD OPERA IDIOMAS 2009-2013}

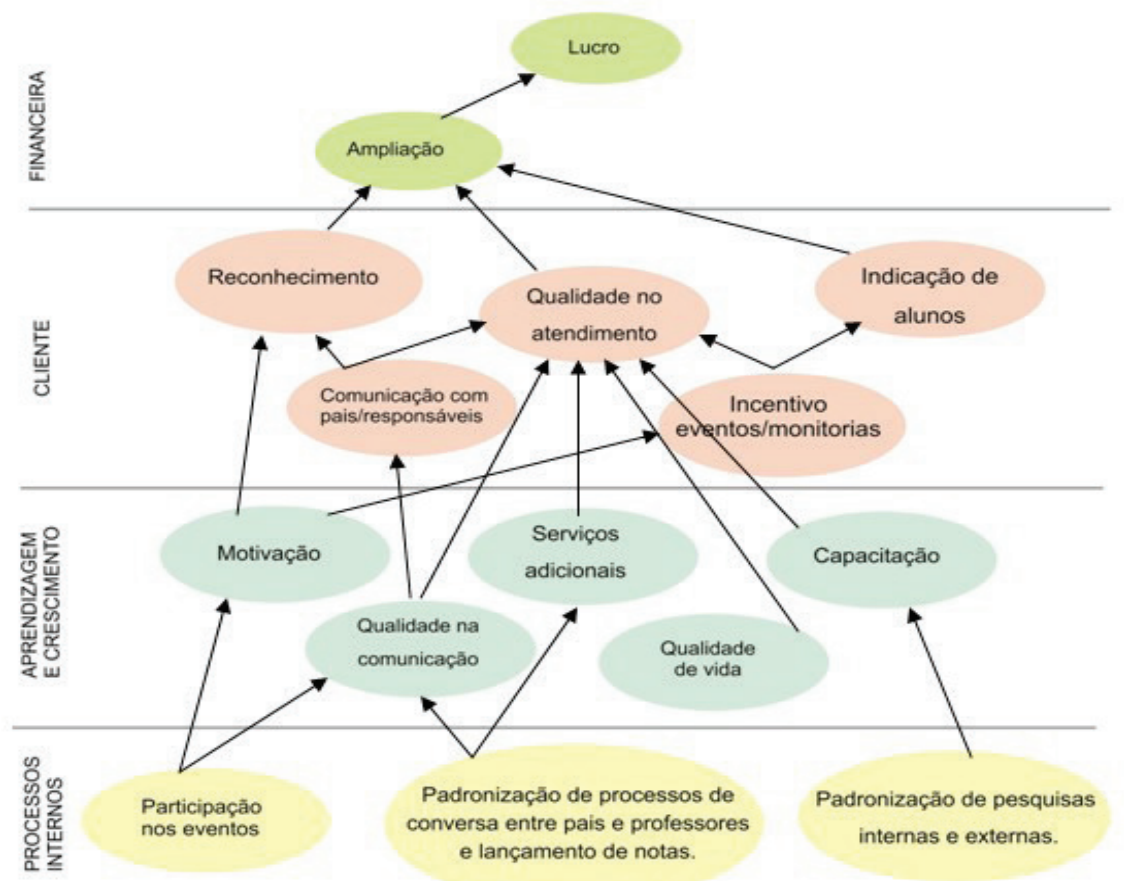

FONTE: Dados da empresa/ elaborado pelos autores

FIGURA 5- INDICADORES DE DESEMPENHO

\begin{tabular}{c|l|l|l}
\hline PERSPECTIVAS & \multicolumn{1}{|c|}{ OBJETIVOS } & \multicolumn{1}{|c}{ METAS } & \multicolumn{1}{c}{ INDICADORES } \\
\hline FINANCEIRA & Crescimento & $\begin{array}{l}\text { Aumento em } \\
10 \%\end{array}$ & Lucro operacional \\
\hline CLIENTES & Fidelização dos alunos & $\begin{array}{l}\text { Aumento de ma- } \\
\text { triculas em 20\% } \\
\text { e retenção de } \\
75 \%\end{array}$ & $\begin{array}{l}\text { Número de alunos } \\
\text { Número de rematrícula } \\
\text { Número de trancamentos e desistências }\end{array}$ \\
\hline
\end{tabular}




\begin{tabular}{c|l|l|l}
\hline PROCESSOS INTERNOS & $\begin{array}{l}\text { Qualidade de comunica- } \\
\text { ção com os responsáveis } \\
\text { e envio de notas. }\end{array}$ & $100 \%$ & $\begin{array}{l}\text { Prazo de entrega de certificados e boletins e } \\
\text { número de notas comunicadas ou acessadas }\end{array}$ \\
\hline $\begin{array}{c}\text { APRENDIZADO E } \\
\text { CRESCIMENTO }\end{array}$ & $\begin{array}{l}\text { Qualidade de vida no no } \\
\text { trabalho }\end{array}$ & $\begin{array}{l}\text { Aumentar em } \\
50 \%\end{array}$ & $\begin{array}{l}\text { Número de demissões ou desligamentos } \\
\text { \% de funcionários que aumentaram o grau } \\
\text { de instrução ou cursos. }\end{array}$ \\
\hline
\end{tabular}

\section{Fonte: Primária}

Vale ressaltar que a parte final do mapa obtido no processo é apresentado na Figura 3 e foi construída, conforme orienta Kaplan (2000) num processo de cima para baixo. Conforme Kaplan (2000), a leitura é realizada de cima para baixo, com o uso de preposições "se" e "então", demonstrando as relações de causa e efeito, entre um objetivo e outro.

Nota-se também que o desenho do mapa foi confeccionado em três fases. A primeira é referente à hierarquização dos níveis (financeiro, cliente, aprendizado e crescimento e processos internos), os quais são identificados por meio da missão e da visão da empresa. A segunda refere-se aos objetivos estratégicos que são extraídos, em parte, da missão e visão, e, em parte, dos pontos fortes e fracos e a terceira fase que se refere à identificação das linhas estratégicas. Por esta razão, parte-se da base do mapa e busca-se relacionar um objetivo ao seguinte, até chegar ao topo do mapa.
A conquista da vantagem competitiva ocorre quando se trabalha paralelamente com o mapa e o painel de desempenho, já que este apresenta indicadores vinculados aos objetivos além das metas a serem alcançadas. Por esta razão, verifica-se que um dos maiores benefícios da utilização do mapa é obter uma representação visual dos objetivos da empresa de forma clara e fácil de ser compreendida por todos os integrantes do processo.

Por meio da elaboração do BSC, foi possível a tradução da missão, o delineamento da estratégia e dos objetivos em medidas segmentadas nas quatro perspectivas permitindo uma visualização e uma comunicação mais efetivas para disseminar a missão e a estratégia, utilizando indicadores para transmitir à direção sobre os veículos de sucesso atual e futuros.

\section{CONCLUSÕES E RECOMENDAÇÕES FINAIS}

O Balanced Scorecard é um sistema de avaliação de desempenho empresarial que complementa as medições financeiras com avaliações sobre o clien-

te, identifica os processos internos que devem ser polidos, verifica as possibilidades de aprendizado e crescimento e ainda analisa as condições de melhora 
no âmbito de recursos humanos, sistemas e capacitação. Diante desta realidade, percebe-se que uma empresa que implementa o BSC tem a consciência da necessidade em conquistar bom desempenho em várias dimensões e não somente através de indicadores financeiros. Segundo Kaplan (2002), o aprendizado e o crescimento são aspectos-chave porque formam a base da melhoria da qualidade e da inovação.

Com relação à empresa objeto do estudo, verifica-se que a utilização do BSC permitiu a articulação da estratégia e auxiliou no alinhamento das diligências grupais, das específicas por cargo e das iniciativas organizacionais desde quando o mapa e os quadros geraram uma visualização mental essencial para o desenvolvimento da respectiva trajetória estratégica. Sabe-se que algumas pequenas empresas trabalham com um sistema de planejamento e controle de cima para baixo, no qual a alta direção define as estratégias e divulga as metas para os demais níveis da empresa, distribuindo as ordens para que tudo seja executado.

O curso de idiomas Opera, ao contrário, visualizou a própria empresa - composta em sua maioria de professores com nível superior completo e pós graduação
- como pessoas de grande capacidade intelectual; por esta razão, a direção da empresa afirma que ao iniciar o processo de feedback estratégico, percebeu um grande avanço no alcance das metas estabelecidas. A mesma justifica que conseguiu comunicar a todos exatamente o que a empresa pretendia alcançar nos anos de 2010 a 2013 e, com a visualização do mapa estratégico, todos tiveram os conhecimentos necessários para fazer sugestões sobre como implementar as estratégias traçadas pela direção da empresa.

Levando em consideração a demonstração de como sucede o planejamento estratégico em um curso de idiomas, conclui-se que a construção de um de Balanced Scorecard - ainda que em uma empresa de pequeno porte - é possível, viável e pode ser baseado em termos similares aos utilizados em grandes organizações. Neste trabalho, recomenda-se o acompanhamento da construção do BSC com o intuito de verificar se os indicadores e as ações estabelecidas geram diferenciação em relação ao desempenho organizacional, afinal, a partir do momento em que são adotados os passos definidos na abordagem do referencial teórico e respeitadas as restrições e características de cada empresa o BSC tende a ser bem sucedido

\section{REFERÊNCIAS}

ANSOFF, H I. Estratégia Empresarial, Mcgraw Hill do Brasil Ltda. São Paulo, 1977.

KAPLAN, R. S.; NORTON, D. P. Organização orientada para a estratégia: como as empresas que adotam o balanced scorecard prosperam no novo ambiente de negócios. Rio de Janeiro: Campus, 2000.

KAPLAN, R. S.; NORTON, D. P. Kaplan e Norton na prática. 3. ed. Rio de Janeiro: Elsevier, 2004.

MACDONALD, Raquel Purnhagen. Um sistema de Avaliação de Desempenho Fundamentado no Balanced Scorecard: implantação em uma empresa Alemã de Médio Porte. 2003. 133 f. Dissertação (Mestrado em Engenharia de Produção) - Universidade Federal de Santa Catarina, Florianópolis, 2003.

MALHOTRA, Naresh K. Pesquisa de Marketing: Uma Orientação Aplicada, São Paulo, Bookman, 2006. 
PORTER, M.E. Estratégia Competitiva: técnica para análise da indústria e da concorrência. Rio de Janeiro: Elsevier, 2004.

REZENDE, J.F. Balanced Scorecard e a gestão do capital intelectual: alcançando a performance balanceada na economia do conhecimento. 2. ed. Rio de Janeiro: Elsevier, 2003.

SLACK, N.; CHAMBERS, S.; JOHNSTON, R. Administração da Produção. 2. ed. São Paulo. Atlas, 2002.

SOARES, Antonio Carlos S. Qualidade: Estratégia de Competitividade Industrial: Uma Análise na Indústria Sul Brasileira. 1999, Dissertação (Mestrado em Engenharia de Produção). Universidade Federal de Santa Catarina.

VERGARA, Sylvia Constant. Projetos e Relatórios de Pesquisa em Administração. 5.ed. São Paulo: Atlas, 2004. 